\title{
Olfactory dysfunction is worse in primary ciliary dyskinesia compared with other causes of chronic sinusitis in children
}

\author{
Massimo Pifferi, ${ }^{1}$ Andrew Bush, ${ }^{2}$ Michele Rizzo, ${ }^{1}$ Alessandro Tonacci, ${ }^{3}$ Maria Di Cicco, ${ }_{1}$ \\ Martina Piras, ${ }_{1}^{1}$ Fabrizio Maggi, ${ }^{4}$ Giulia Paiola, ${ }^{5}$ Angela Michelucci, ${ }^{6}$ Angela Cangiotti, ${ }^{7}$ \\ Diego Peroni, ${ }^{1}$ Davide Caramella, ${ }^{8}$ Attilio L Boner ${ }^{5}$
}

\begin{abstract}
- Additional material is published online only. To view please visit the journal online (http://dx.doi.org/10.1136/ thoraxjnl-2017-210661).

'Department of Paediatrics, University Hospital of Pisa, Pisa, Italy

${ }^{2}$ Imperial College and Royal Brompton Hospital, London, UK ${ }^{3}$ Institute of Clinical Physiology, National Research Council of Italy (IFC-CNR), Pisa, Italy ${ }^{4}$ Department of Clinical and Experimental Medicine, University Hospital of Pisa, Pisa, Italy

${ }^{5}$ Department of Paediatrics, University Hospital of Verona, Verona, Italy

${ }^{6}$ Laboratory of Molecular Genetics, University Hospital of Pisa, Pisa, Italy

${ }^{7}$ Electron Microscopy Unit, University Hospital of Ancona, Ancona, Italy

${ }^{8}$ Department of Diagnostic and Interventional Radiology, University Hospital of Pisa, Pisa, Italy
\end{abstract}

\section{Correspondence to}

Dr Massimo Pifferi, Department of Pediatrics, University Hospital of Pisa, Pisa 56126, Italy; m.pifferi@med.unipi.it

Received 18 June 2017 Revised 2 February 2018 Accepted 12 February 2018 Published Online First 28 February 2018 thoraxjnl-2018-211620

\section{Check for updates}

To cite: Pifferi M, Bush A, Rizzo M, et al. Thorax 2018;73:980-982

\section{ABSTRACT}

Cilia have multiple functions including olfaction. We hypothesised that olfactory function could be impaired in primary ciliary dyskinesia (PCD). Olfaction, nasal nitric oxide (nNO) and sinus $\mathrm{CT}$ were assessed in patients with $P C D$ and non-PCD sinus disease, and healthy controls (no CT scan). PCD and non-PCD patients had similar severity of sinus disease. Despite this, defective olfaction was more common in patients with $\mathrm{PCD}(\mathrm{P}<0.0001)$ and more severe in patients with PCD with major Transmission Electron Microscopy (TEM) abnormalities. Only in classical PCD did olfaction inversely correlate with sinusitis and nNO. We speculate that defective olfaction in PCD is primary in nature.

\section{INTRODUCTION}

Cilia are evolutionary conserved organelles subdivided into primary (non-motile, with multiple signalling and sensory functions), nodal (defining situs) and motile (propelling mucus across epithelia). ${ }^{1}$ There is more overlap than hitherto appreciated between primary and motile ciliopathies. ${ }^{2}$ Non-motile cilia on the renal tubular epithelial cells and in the retina are defective in polycystic kidney disease and retinitis pigmentosa, respectively, both of which may be associated with primary ciliary dyskinesia (PCD), a motile ciliopathy characterised by impaired mucociliary clearance resulting in recurrent upper and lower airway infection. ${ }^{3}$ Primary cilia are involved in olfaction in transgenic mice ${ }^{4}$ and in patients with Bardet-Biedl syndrome ${ }^{5}$ who display impaired olfactory function primarily due to dysfunctional basal bodies and/or cilia, as well as having a PCD-like respiratory phenotype.

We hypothesised that olfactory function is impaired in PCD, and we evaluated its relationship with nasal nitric oxide (nNO), which modulates olfactory transduction, ${ }^{6}$ and with the extent of paranasal sinus involvement. ${ }^{7}$ We evaluated patients with non-PCD sinus disease in order to determine if any dysfunction was ciliopathy related, rather than secondary to infection and inflammation, and also normal controls free of any sinus disease.

\section{MATERIALS AND METHODS}

All subjects age $\geq 6$ years with a diagnosis of $P C D$ on standard protocols were consecutively enrolled. ${ }^{8}$ Each evaluation was performed when subjects had been free from signs and symptoms of acute respiratory infection for $\geq 4$ weeks. nNO was measured using standard methodology. ${ }^{9}$

Olfactory function was assessed using the Sniffin' Sticks Extended Test (Burghart Medizintechnik, $\mathrm{GmbH}$, Wedel, Germany), which consists of three different subtests, assessing the olfactory sensitivity (threshold), discrimination and identification. ${ }^{10}$ All patients underwent unenhanced CT scans. The degree of paranasal sinuses inflammation was assessed using a modified Lund-Mackay system. ${ }^{11}$ Full details of all methods are online (see online supplementary material 1).

\section{RESULTS}

Demographic, clinical and laboratory characteristics of study population and their comparison with healthy controls or with patients with non-PCD sinusitis are shown in table 1. No control patient had any impairment of olfaction. Olfactory assessments showed significant impairment of all parameters in patients with PCD compared with controls and non-PCD sinusitis. Anosmia and hyposmia were more common $(\mathrm{P}<0.0001)$ in PCD, being present in $18(29 \%)$ and $28(45 \%)$ out of 62 patients, respectively, than in patients with non-PCD sinus disease (hyposmia in 6 of 25 (24\%), anosmia $0 / 25$ ). Moreover, in patients with PCD, a significant inverse correlation was found between each olfactory assessment and the modified LundMackay score.

In PCD, there was a significant inverse correlation between Discrimination, TDI score, and TDI extended score and sinus aplasia or hypoplasia scores $(\mathrm{P}=0.013, \mathrm{r}=-0.320 ; \mathrm{P}=0.029$, $\mathrm{r}=-0.284 ; \mathrm{P}=0.025, \mathrm{r}=-0.292$, respectively) and a positive correlation between each olfactory assessment and nNO levels. In non-PCD sinus disease, only Threshold and Discrimination were inversely correlated with the modified Lund-Mackay score $(\mathrm{P}=0.001, \quad \mathrm{r}=-0.607 ; \mathrm{P}=0.025, \quad \mathrm{r}=-0.446$, respectively). In this group, there was also a positive correlation between Threshold, TDI score, and TDI extended score and $\mathrm{nNO}(\mathrm{P}<0.001, \mathrm{r}=0.977$; $\mathrm{P}=0.012, \mathrm{r}=0.496 ; \mathrm{P}=0.034, \mathrm{r}=0.426$, respectively), while there were no correlations between any test of Discrimination and nNO.

Post hoc, we related the data to ultrastructural abnormality; there was a lower prevalence of olfactory dysfunction (hyposmia 33\%, anosmia $7 \%$, normal olfaction 60\%) in DNAH11 PCD $(\mathrm{P}=0.0005)$ compared with other groups. Patients 
Table 1 Characteristics of study population

\begin{tabular}{|c|c|c|c|c|c|c|}
\hline \multirow[b]{2}{*}{ Clinical data } & \multirow[b]{2}{*}{ PCD } & \multirow[b]{2}{*}{ Sinusitis } & \multirow[b]{2}{*}{ Controls } & \multicolumn{3}{|c|}{ Tukey's test } \\
\hline & & & & $\begin{array}{l}\mathbf{P} \\
\text { PCD } \\
\text { /sinusitis }\end{array}$ & $\begin{array}{l}\mathrm{P} \\
\mathrm{PCD} \\
\text { /controls }\end{array}$ & $\begin{array}{l}\mathrm{P} \\
\text { sinusitis/ } \\
\text { controls }\end{array}$ \\
\hline Subjects, n & $62^{*}$ & 25 & 43 & - & - & - \\
\hline Men n (\%)† & $31(50)$ & $14(56)$ & $19(44)$ & - & - & - \\
\hline Children $\mathrm{n}(\%)$ & $23(37)$ & $10(40)$ & $16(37)$ & - & - & - \\
\hline Age, years, median (L-UQ) & $21.4(15.9$ to 36.1$)$ & 21.5 (14.9 to 40.2$)$ & 26.3 (11.9 to 28.6$)$ & 0.879 & 0.359 & 0.276 \\
\hline Nasal nitric oxide, $\mathrm{nL} /$ min median (L-UQ) & 31.8 (16.3 to 49.8$)$ & 77.6 (72.0 to 82.2$)$ & 200.7 (197.9 to 201.7) & $<0.0001$ & $<0.0001$ & $<0.0001$ \\
\hline \multicolumn{7}{|l|}{ Olfactory assessment (mean) } \\
\hline Threshold $(95 \% \mathrm{Cl})$ & 3.6 (3.0 to 4.2$)$ & $4.6(4.2$ to 4.9$)$ & $6.2(5.9$ to 6.5$)$ & 0.040 & $<0.0001$ & $<0.001$ \\
\hline Discrimination $(95 \% \mathrm{Cl})$ & $8.4(7.2$ to 9.4$)$ & 11.5 (10.8 to 11.9$)$ & $12.3(11.8$ to 12.8$)$ & 0.001 & $<0.0001$ & 0.479 \\
\hline Blue identification $(95 \% \mathrm{CI})$ & 9.3 (8.2 to 10.2$)$ & $11.6(11.1$ to 12.2$)$ & 12.5 (11.7 to 13.2$)$ & 0.007 & $<0.0001$ & 0.513 \\
\hline Purple identification $(95 \% \mathrm{Cl})$ & $8.6(7.6$ to 9.6$)$ & $11.7(11.1$ to 12.1$)$ & 12.6 (12.0 to 13.2$)$ & 0.0002 & $<0.0001$ & 0.447 \\
\hline TDI score $(95 \% \mathrm{CI})$ & 21.2 (18.7 to 23.6$)$ & $27.6(26.6$ to 28.6$)$ & 31.1 (29.9 to 32.2) & 0.001 & $<0.0001$ & 0.142 \\
\hline TDI extended score $(95 \% \mathrm{Cl})$ & $29.8(26.4$ to 33.2$)$ & 39.3 (37.9 to 40.6$)$ & 43.7 (42.1 to 45.3$)$ & 0.0003 & $<0.0001$ & 0.187 \\
\hline \multicolumn{7}{|l|}{ CT scanning of paranasal sinuses } \\
\hline Modified Lund-Mackay score, median (L-UQ) & 12.0 (9.8 to 17.7$)$ & $11.0(9.0$ to 14.0$)$ & NA & 0.100 & - & - \\
\hline Sinus aplasia or hypoplasia score, median (L-UQ) & $3.0(0.0$ to 4.0$)$ & $3.0(1.25$ to 4.0$)$ & NA & 0.920 & - & - \\
\hline
\end{tabular}

${ }^{*} \mathrm{CT}$ scanning of paranasal sinuses in 57 patients with PCD.

tMen vs women: $\mathrm{P}=0.634$ ( $\chi^{2}$ test).

L-UQ, lower-upper quartile; NA, not applicable; PCD, primary ciliary dyskinesia; TDI,Threshold Discrimination Identification.

with PCD with major TEM abnormalities also had significantly lower nNO levels (table 2) and olfactory assessments than in patients with DNAH11 gene mutations.

All olfactory assessments in classical PCD, but not in DNAH11 PCD, were significantly lower than in patients with non-PCD sinus disease.

Full results are online (see online supplementary material, figures E1-E8, tables E1-E3).

\section{DISCUSSION}

There were significant impairments in all olfactory assessments in patients with PCD compared with controls and non-PCD sinusitis. Olfactory dysfunction was worse in those patients with PCD with major ultrastructural abnormalities. This suggests that for ciliary defects with relatively preserved function, olfactory sensation is less compromised despite there being similar sinus disease on high-resolution CT. Olfactory impairment was more severe in patients with lower levels of $\mathrm{nNO}$ and in those with higher modified Lund-Mackay scores, suggesting that the severity of sinus disease may also have an impact on olfaction, especially in subjects with major axonemal ultrastructural defects. Thus, in patients with PCD, there appears to be an impairment of motile cilia and also a reduced function of primary (sensory) cilia. We accept that the absence of a subjective measure of sinusitis such

Table 2 Characteristics of study population

\begin{tabular}{|c|c|c|c|c|c|c|c|}
\hline \multirow[b]{2}{*}{ Clinical data } & \multirow[b]{2}{*}{ Classical PCD* } & \multirow[b]{2}{*}{ DNAH11 PCD } & \multicolumn{5}{|l|}{ Tukey's test } \\
\hline & & & $\begin{array}{l}\text { P } \\
\text { classical PCD/ } \\
\text { DNAH11 PCD }\end{array}$ & $\begin{array}{l}\text { P } \\
\text { classical PCD/ } \\
\text { sinusitis }\end{array}$ & $\begin{array}{l}\text { P } \\
\text { classical PCD/ } \\
\text { controls }\end{array}$ & $\begin{array}{l}\text { P } \\
\text { DNAH11 PCD/ } \\
\text { sinusitis }\end{array}$ & $\begin{array}{l}\text { P } \\
\text { DNAH11 } \\
\text { PCD/ } \\
\text { controls }\end{array}$ \\
\hline Subjects, nt & $47 \S$ & 15 & - & - & - & - & - \\
\hline Men, n (\%)‡ & $25(53)$ & $6(40)$ & - & - & - & - & - \\
\hline Children, n (\%) & $17(36)$ & $6(40)$ & - & - & - & - & - \\
\hline Age, years, median (L-UQ) & 22.1 (15.6 to 40.1$)$ & 20.1 (16.5 to 28.4$)$ & 0.726 & 0.998 & 0.358 & 0.709 & 0.999 \\
\hline $\begin{array}{l}\text { Nasal nitric oxide, } \mathrm{nL} / \mathrm{min} \\
\text { median (L-UQ) }\end{array}$ & 22.5 (14.6 to 36.8$)$ & 54.4 (33.6 to 81.6) & 0.002 & $<0.0001$ & $<0.0001$ & 0.079 & $<0.0001$ \\
\hline \multicolumn{8}{|l|}{ CT scanning of paranasal sinuses* } \\
\hline $\begin{array}{l}\text { Modified Lund-Mackay score, } \\
\text { median (L-UQ) }\end{array}$ & $12.0(10.0$ to 18.0$)$ & 10.9 (9.8 to 17.7$)$ & 0.898 & 0.989 & - & 0.867 & - \\
\hline $\begin{array}{l}\text { Sinus aplasia or hypoplasia } \\
\text { score, median (L-UQ) }\end{array}$ & $3.0(0.0$ to 5.0$)$ & $1.0(0.0$ to 3.5$)$ & 0.095 & 0.970 & - & 0.514 & - \\
\hline
\end{tabular}

*With typical ultrastructural abnormalities.

tClinical data of sinusitis and controls are shown in table 1.

¥Men vs women: $P=0.373$ ( $\chi^{2}$ test).

$\S C T$ scanning of paranasal sinuses in 42 patients with classical PCD.

L-UQ, lower-upper quartile; PCD, primary ciliary dyskinesia. 
as the patient-reported outcome measure SNOT-22 or similar is a weakness of the study, and that the Lund-Mackay score is known to correlate poorly with subjective measures.

We have no longitudinal data or measurements in presymptomatic PCD to establish if the defect we found is primary or secondary. Indeed, given that children with PCD are symptomatic long before they could cooperate with olfactory testing, such presymptomatic data are unlikely to be obtained. We favour the hypothesis that there is a primary olfactory defect because olfactory impairment was greater in patients with PCD with major ultrastructural defects than in those with DNAH11 gene mutations and a subtle Outer Dynein Arm (ODA) defect in only the proximal region of respiratory cilia despite there being no differences in the severity of sinus disease, and also olfaction was worse than in non-PCD patients with equivalently severe sinus disease.

Furthermore, low nNO levels and olfactory impairment were more severe in patients with major alterations in ciliary structure than in those with DNAH11 gene mutations; we speculate that there may be a central role for nitric oxide both as mediator of neural transmission as well as a regulator of neurogenesis. ${ }^{12}$ In fact, cellular responses to odorant stimulation require a nitric oxide-induced increase in cGMP in the entire neuron, from cilia-dendrite to the axon terminus-growth cone, ${ }^{6}$ and in an animal model, increased hippocampal and olfactory bulb neurogenesis is associated with increased regional endothelial nitric oxide synthase (NOS-III) expression. ${ }^{13}$ Moreover, the selective loss of $G$ proteins in cilia of olfactory sensory neurons is associated with anosmia, ${ }^{14}$ and gene therapy rescues cilia defects and restores olfactory function in a mammalian ciliopathy model. ${ }^{15}$

In summary, despite the relatively small number of patients and the need of confirmations with larger studies, impairment of olfaction in patients with PCD seems to be of neural origin, similar to that seen in the primary ciliopathies.

Acknowledgements The authors thank the PCD patients and/or their parents for participation in the study. We also express our gratitude to Luigi Cappelli, President, and Palmina Fraschilla, Letizia Andolfi, Elisabetta Santarelli and Alessia Donnini, Board Members of Italian PCD-Kartagener Syndrome Association, for constant support of our research. Moreover, the authors thank the European COST (Cooperation in Science and Technology) BM1407 BEAT-PCD for constant support of our research.

Contributors MPif, $A B$ and $A L B$ designed the study, analysed all data and wrote the manuscript. MR, AT, MDC, MPir, AC and AM collected the experimental data and contributed to data evaluation. DC collected the radiological data and contributed to data evaluation. FM and GP performed statistical analyses and contributed to data evaluation. DP contributed to interpretation of data and helped to draft the manuscript for important intellectual content. All authors approved the version of the manuscript to be submitted. All authors take responsibility for the integrity of the data and the accuracy of the data analysis.

Funding This research received no specific grant from any funding agency in the public, commercial or not-for-profit sectors.

Competing interests None declared.

Patient consent Obtained.

Ethics approval Hospital Ethical Committee of Pisa.

Provenance and peer review Not commissioned; externally peer reviewed.

(c) Article author(s) (or their employer(s) unless otherwise stated in the text of the article) 2018. All rights reserved. No commercial use is permitted unless otherwise expressly granted.

\section{REFERENCES}

1 Horani A, Ferkol TW. Primary ciliary dyskinesia and associated sensory ciliopathies. Expert Rev Respir Med 2016;10:569-76.

2 Shah AS, Ben-Shahar Y, Moninger TO, et al. Motile cilia of human airway epithelia are chemosensory. Science 2009;325:1131-4.

3 Ostrowski LE, Dutcher SK, Lo CW. Cilia and models for studying structure and function. Proc Am Thorac Soc 2011;8:423-9.

4 Wong ST, Trinh K, Hacker B, et al. Disruption of the type III adenylyl cyclase gene leads to peripheral and behavioral anosmia in transgenic mice. Neuron 2000;27:487-97.

5 Tadenev AL, Kulaga HM, May-Simera HL, et al. Loss of Bardet-Biedl syndrome protein-8 (BBS8) perturbs olfactory function, protein localization, and axon targeting. Proc Natl Acad Sci U SA 2011;108:10320-5.

6 Pietrobon M, Zamparo I, Maritan M, et al. Interplay among CGMP, CAMP, and Ca2+ in living olfactory sensory neurons in vitro and in vivo. J Neurosci 2011;31:8395-405.

7 Elsherif HS, Landis BN, Hamad MH, et al. Olfactory function and nasal nitric oxide. Clin Otolaryngol 2007;32:356-60.

8 Lucas IS, Barbato A, Collins SA, et al. European Respiratory Society guidelines for the diagnosis of primary ciliary dyskinesia. Eur Respir J 2017;49:1601090.

9 Baraldi E, de Jongste JC. European Respiratory Society/American Thoracic Society (ERS/ATS) Task Force. Measurement of exhaled nitric oxide in children, 2001. Eur Respir I 2002;20:223-37.

10 Hummel T, Kobal G, Gudziol H, et al. Normative data for the "Sniffin' Sticks" including tests of odor identification, odor discrimination, and olfactory thresholds: an upgrade based on a group of more than 3,000 subjects. Eur Arch Otorhinolaryngol 2007:264:237-43.

11 Hopkins C, Browne JP, Slack R, et al. The Lund-Mackay staging system for chronic rhinosinusitis: how is it used and what does it predict? Otolaryngol Head Neck Surg 2007;137:555-61.

12 Garthwaite J. Glutamate, nitric oxide and cell-cell signalling in the nervous system. Trends Neurosci 1991;14:60-7.

13 Kronenberg G, Gertz K, Baldinger T, et al. Impact of actin filament stabilization on adult hippocampal and olfactory bulb neurogenesis. J Neurosci 2010;30:3419-31.

14 McEwen DP, Koenekoop RK, Khanna H, et al. Hypomorphic CEP290/NPHP6 mutations result in anosmia caused by the selective loss of $\mathrm{G}$ proteins in cilia of olfactory sensory neurons. Proc Natl Acad SciU S A 2007:104:15917-22.

15 McIntyre JC, Davis EE, Joiner A, et al. Gene therapy rescues cilia defects and restores olfactory function in a mammalian ciliopathy model. Nat Med 2012;18:1423-8. 